\title{
Unlocking the Doors to Patient Satisfaction in Pediatric Orthopaedics
}

\author{
Frederick B. Peng, BS \\ Thomas Jefferson University \\ James F. Burrows, MBA \\ Nemours/Alfred I. duPont Hospital for Children \\ Eric D. Shirley, MD \\ Nemours Children's Specialty Care \\ Paul Rosen, MD, MPH, MMM \\ Nemours/Alfred I. duPont Hospital for Children
}

Follow this and additional works at: https://jdc.jefferson.edu/pedsposters

Part of the Orthopedics Commons, and the Pediatrics Commons

\section{Let us know how access to this document benefits you}

\section{Recommended Citation}

Peng, BS, Frederick B.; Burrows, MBA, James F.; Shirley, MD, Eric D.; and Rosen, MD, MPH, MMM, Paul, "Unlocking the Doors to Patient Satisfaction in Pediatric Orthopaedics" (2015). Department of Pediatrics Posters. 1.

https://jdc.jefferson.edu/pedsposters/1

This Article is brought to you for free and open access by the Jefferson Digital Commons. The Jefferson Digital Commons is a service of Thomas Jefferson University's Center for Teaching and Learning (CTL). The Commons is a showcase for Jefferson books and journals, peer-reviewed scholarly publications, unique historical collections from the University archives, and teaching tools. The Jefferson Digital Commons allows researchers and interested readers anywhere in the world to learn about and keep up to date with Jefferson scholarship. This article has been accepted for inclusion in Department of Pediatrics Posters by an authorized administrator of the Jefferson Digital Commons. For more information, please contact: JeffersonDigitalCommons@jefferson.edu. 
Unlocking the Doors to Patient Satisfaction in Pediatric Orthopaedics

Frederick B. Peng BS, ${ }^{1}$ James F. Burrows MBA, ${ }^{2}$ Eric D. Shirley MD, ${ }^{3}$ Paul Rosen MD, MPH, MMM²

${ }^{1}$ Sidney Kimmel Medical College, Thomas Jefferson University, Philadelphia, PA, ${ }^{2}$ Nemours/Alfred I. duPont Hospital for Children, Wilmington, DE

Nemours.

\section{Background}

Many hospitals continue to struggle to improve patient satisfaction as the identification of tangible quality improvement areas remains difficult [1].

- Medicare hospital payments are linked to patient satisfaction and hospitals' HCAHPS scores, which has contributed to the growing influence of patient satisfaction measures [1-3].

- Investigation into the major drivers of patient satisfaction in the pediatric clinical arena has not been thoroughly pursued.

- To determine the main drivers of patient experience in pediatric orthopaedics, we performed an analysis of patient satisfaction surveys collected from outpatient pediatric orthopaedic practices at 5 locations in 3 states.

- Hypothesis: the patient-physician relationship is the most important factor in patients' assessment of their experiences.

- These results may have significance in aiding pediatric orthopaedic clinics in their Quality Assurance/Quality Improvement plans of enhancing the patient experience.

\section{Methods}

- Retrospective analysis of patient satisfaction surveys following visits to Nemours Children's pediatric orthopaedic ambulatory clinics between 2012 and 2014

- Jacksonville, Orlando, and Pensacola (Florida), as well as Wilmington (Delaware) and Newtown Square (Pennsylvania).

- 6,195 responses reviewed, 15\% return rate.

- Variables measured on a 5 point Likert numerical scale: - ' 1 ' being 'very poor' and ' 5 ' being 'very good.' - Patient satisfaction defined as 'Likelihood of Your Recommending our
Practice to Others' or LTR.

- Statistical analysis using top box scores ('5' or 'very good') consisting of month over month Pearson product-moment correlation coefficients

was used to determine the factors most predictive of LTR.

- Patient-physician relationship variables:

- 'Friendliness/Courtesy of Care Provider'

- 'Care Provider's Explanations of Problem/Condition'

- 'Care Provider's Concern for Questions/Worries'

- 'Care Provider's Efforts to Include You in Decisions about Your Child's Treatment'

- 'Care Provider's Information about Medications'

- 'Care Provider's Instructions for Follow-Up Care'

- 'Care Provider Spoke Using Clear Language'

- 'Time Care Provider Spent with Patient'

- 'Patients' Confidence in Care Provider'

- 'Likelihood of Recommending Care Provider'

\section{Results} Figure 1: Top four survey responses with the strongest
relationships to LTR
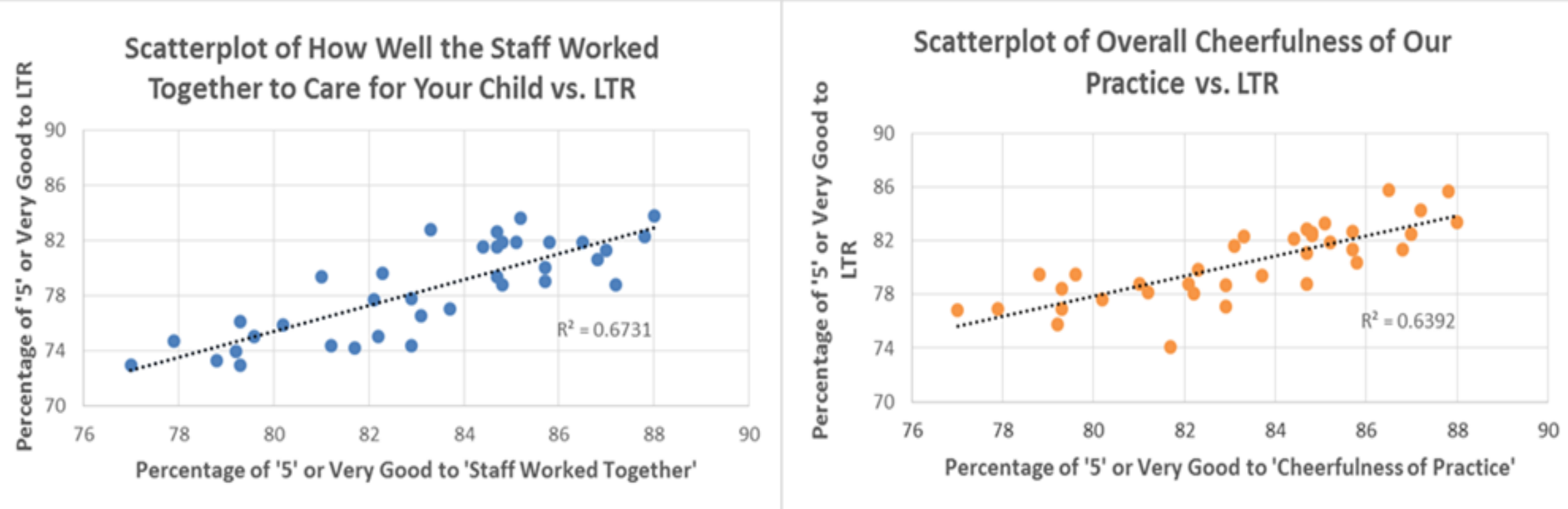

Scatterplot of Friendliness/Courtesy of the Care
Provider vs. LTR

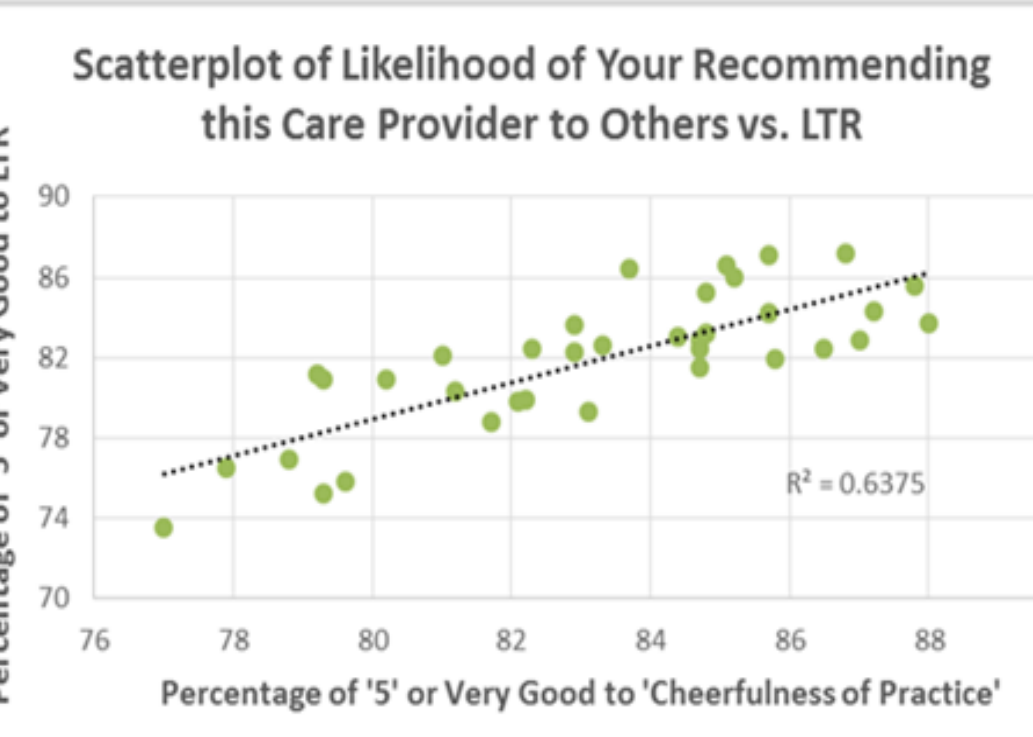

- Each graph contains 36 data points, where each data point corresponds with single month average percentages of ' 5 ' or 'very good' responses over three years.

- $r^{2}$ quantifies the extent to which an independent variable can predict the dependent variable. Specifically, $0.6731,0.6451,0.6392$, and 0.6375 all represent the proportion of variance in LTR that can be explained by the measured variables.

Table 1: List of Survey Responses/Questions with their corresponding correlation coefficients

\begin{tabular}{|l|c|}
\hline Survey Response/Question & Correlation Coefficient $(\mathbf{r})$ \\
\hline Strong Relationships $(\boldsymbol{r}>\mathbf{0 . 6})$ & 0.82 \\
\hline Staff Worked Together & 0.80 \\
\hline Friendliness/Courtesy of Care Provider & 0.80 \\
\hline Cheerfulness of Practice & 0.80 \\
\hline Likelihood of Recommending Care Provider & 0.78 \\
\hline Care Provider's Information about Medications & 0.76 \\
\hline Our Concern for Patients' Privacy & 0.75 \\
\hline Patients' Confidence in Care Provider & \\
\hline
\end{tabular}

- Survey responses with the strongest correlation to LTR included: - 'How Well the Staff Worked Together to Care for Your Child' $(r=0.82)$ - 'Friendliness/Courtesy of the Care Provider' $(r=0.80)$

- 'Overall Cheerfulness of Our Practice' $(r=0.80)$

- 'Likelihood of Your Recommending this Care Provider to Others' $(r=0.80)$

- 'Information the Care Provider Gave You About Medications (if any)' $(r=0.78)$

\section{Discussion}

Study Limitations

- Possible response bias, since families with either positive or negative experiences are more likely to be represented in low response rates.

- Healthcare industry finds validity in survey measurements despite the controversy surrounding low response rates.

- Sensitivity regarding the use of top box scores: physicians argue that 4's should be included with 5's in measuring high performance. If top box scores were more inclusive, then there would be little room for improvement.

- This analysis was performed on patients seen in pediatric academic practices which may make the results less generalizable to the broader orthopaedic clinical setting.

Conclusions

- Key drivers: mixture of the patient-physician relationship, overall cheerfulness of the practice, and interact

- Future efforts to enhance the patient experience should capitalize on these measures.

- Patients and their families may value similar qualities in their healthcare providers in other pediatric subspecialties. However, these results in other subspecialties.

Table 2: Suggestions that may improve patient
satisfaction in pediatric orthopaedic care settings \begin{tabular}{|l|l}
\hline Main Drivers of Patient & Improvement Suggestions
\end{tabular}

Satisfaction

Staff Worked Togethe

Friendliness/Courtesy of Care

Provider

Cheerfulness of Practice

Minimize patient hand off to avoid redundancy and enhance patients' comfort through Address patients directly, listen to families' warmly, greet everyone in the family, and wash hands before examining/touching patients.

\begin{tabular}{l|l|l} 
Engage patients with fun books and toys in \\
waiting areas, and introduce themed days.
\end{tabular} \begin{tabular}{|l|l|}
\hline $\begin{array}{l}\text { Likelihood of Recommending Care } \\
\text { Provider }\end{array}$ & $\begin{array}{l}\text { Avoid using medical jargon, empathize with any } \\
\text { emotional concerns, and answer all questions in a }\end{array}$ \\
\hline
\end{tabular}

Care Provider's Information about Medications Provide clear instructions both verbally and writing, and ask families to clarify their

\section{References}

1. Maister, D. H. (2005). The psychology of waiting lines.

2. Werner, R. M., Kolstad, J. T., Stuart, E. A., \& Polsky, D. (2011). The effect of pay- 690 - 698. in hospitals: Lessons for quality improvement. Health Affairs (Project Hope), 30(4), 690-698.

3. Zusman, E. E. (2012). HCAHPS replaces press ganey survey as quality measure for patient hospital
experience. Neurosurgery. 71(2), N21-4. doi: $10.1227 / 01$ neu 0000417536.07871 .ed [doi] 